Revista Iberoamericana. Vol. LXVI, Núm. 191, Abril-Junio 2000, 339-345

\title{
LAS MADRES DE LA CALLE PASTEUR: LA LUCHA POR EL PLURALISMO EN LA ARGENTINA
}

\author{
POR \\ Edna Aizenberg \\ Marymount Manhattan College
}

En memoria de mi amiga Susy Kreiman

El 18 de julio de 1994 a las 9:50 de la mañana, un poderoso explosivo estalló en el centro de Buenos Aires. Su objetivo fue el edificio de la Asociación Mutual Israelita Argentina, conocida como la AMIA, institución matriz de la comunidad judeoargentina. A pesar de su objetivo, la bomba no discriminó: más de ochenta personas, judías y no-judías, murieron despedazadas aquel día, y decenas de propiedades —edificios, negocios, y escuelas - fueron destruidas. Las imágenes de la Calle Pasteur al 600 parecían provenir de Sarajevo, Beirut o Kosovo, de alguna ciudad descuartizada por los efectos del odio étnico y la violencia racial.

La Argentina se enorgullece de ser el país más “europeo” de Latinoamérica. Según la retórica oficial, la Argentina es un país homogéneo, poblado por habitantes de origen europeo, con apenas "gotas” de sangre indígena, africana o judía. Las Fuerzas Armadas, cuyo papel dominante en la política argentina es harto y horrorosamente conocido, siempre se han considerado las custodias de los “valores fundamentales de la nación”, con poca tolerancia hacia los portadores de valores no-occidentales o no-cristianos. Nunca han titubeado en defender estos “valores fundamentales" — derivados en última instancia de un hispano-catolicismo de corte medieval— si fuera necesario por medio de la desaparición y la tortura. Los que no pertenecen a esta "esencia nacional” no pueden aspirar a la verdadera argentinidad, escribe el poeta y filósofo Santiago Kovadloff en su poderoso ensayo, "Un lugar en el tiempo: la Argentina como viviencia de los judíos”. Inevitablemente quedan condenados a la marginalización, al no estar dentro del ser argentino.

La bomba que estalló en la AMIA evidencia el penoso hecho que la Argentina, como tantos otros países latinoamericanos, todavía no ha logrado construir una comunidad nacional pluralista. A pesar de sus manías de superioridad y sus aires parisinos, la Argentina es una sociedad dolorosamente latinoamericana, con múltiples problemas de derechos humanos y de igualdad entre ciudadanos de diversas etnias y orientaciones aún sin resolver. La máscara europeísta que cubre la faz de la verdadera Argentina no sólo oculta la existencia de indígenas y mestizos — despectivamente llamados "cabecitas negras" - sino que también esconde la presencia de inmigrantes no provenientes de Europa, como judíos sefarditas y árabes (Por ejemplo, el presidente saliente, Carlos Saúl Menem, es el hijo de 
inmigrantes sirio-musulmanes que tuvo que convertirse al catolicismo para postularse a la presidencia). La máscara europeísta de la verdadera Argentina encubre hasta las diferencias entre los así llamados europeos: descender de un polaco no es lo mismo que descender de un inglés.

La mayoría de los 200,000 judíos de la Argentina, que constituyen la colectividad más grande de Latinoamérica, son de Europa del Este, pero Feierstein, Steimberg o Aizenberg no captan el oído con la misma música que Rodríguez, Anchorena o Borges; tampoco lo hacen su herencia cultural y su bagaje idiomático, anclados en el idish. Ricardo Feierstein, Mario Szichman, Silvia Pláger, Ana María Shúa, Alicia Steimberg y otros escritores han atacado esta discriminación lingüístico-onomástica con una ironía mordaz en sus mejores obras. Escuchemos a Steimberg en su novela, Cuando digo Magdalena:

¿Te acordás que Borges decía que con una de sus abuelas hablaba de una manera y con la otra hablaba de otra manera, y que sólo con el tiempo llegó a enterarse de que estas dos maneras de hablar se llamaban lengua española y lengua inglesa? Bueno, a mí me pasaba algo parecido, sólo que una manera de hablar era el castellano y el otro el idish. Como el idish me sonaba duro y desagradable me negué sistemáticamente a aprenderlo; era un idioma lleno de misterios que podía revelar lo que yo realmente era. Desde muy temprano se me exigió que ocultara o disfrazara lo que yo "realmente” era, y que fingiera ser algo que, curiosamente, también era (61).

Feierstein presenta su ataque en “Aventuras de un apellido”. El protagonista, David Schnaiderman, dialoga con un empleado público:

\begin{abstract}
“¿Apellido?” “Schnaiderman”. “¿Cómo?” La misma historia de siempre, experimentada desde el colegio primario ... "Schnaiderman”, repetís ... "No se ponga nervioso. Lo voy a deletrear". "Mejor será ... que lo escriba usted. Para mí es dificíl copiar nombres EXTRANJEROS ...” “¿Cuál es su nombre, señor”, preguntás. “Héctor García. ¿Por qué?” “¿Y su apellido no es ‘extranjero’, sino ‘argentino’?” “Sí ... Sí señor”. “Es decir usted desciende de una tribu de indios matacos. O tobas. O de los García querandíes. ¿¿Quizá Calfurucá García, un cacique araucano?” ... "No señor. Quise decir que soy 'argentino' porque nací aquí. En esta tierra”. "Yo también nací aquí” (4-5).
\end{abstract}

Y así va, hasta que el empleado ladra que pase el siguiente en la fila, y David Schnaiderman musita:

En realidad, más allá de pirotecnias verbales ... vos sos el judío, el minoritario, el marginal para muchos (6).

La Magdalena de Steimberg también es un ser marginal, con una identidad femenina y judía tan inestable que hasta su nombre es prestado. Cuando digo Magdalena: es sólo una etiqueta provisional.

Durante cien años, desde que la Argentina inició una política pro-inmigratoria destinada a poblar el país con europeos que terminaran con la "barbarie”, los adherentes de un discurso exclusionista han luchado contra los partidarios de un discurso más inclusionista 
que refleje a la nación tal como es. La tragedia de la AMIA, sobre todo la investigación que siguió al crimen, demuestra claramente que esta lucha no ha cesado. Primero, ¿quién puso la bomba? Aparentemente, terroristas internacionales bajo el mandato de Irán. Pero nada es seguro. Más de cinco años después de la explosión todavía "no hay justicia”, para citar el doloroso título de un informe publicado por el Comité Judío Americano:

A pesar de las declaraciones de las autoridades argentinas que se sigue investigando el caso con vigor y seriedad, los que destruyeron el centro más importante de la vida judeoargentina no han sido llevados a la justicia ... Tampoco lo han sido los perpetradores de la explosión que destruyó la embajada de Israel en Buenos Aires dos años antes, explosión en que murieron 29 personas (Kiernan, Still No Justice iii).

¿Por qué tanta impunidad? Según las opiniones más calificadas, existen poderosos intereses locales que no quieren que la investigacíon progrese. ¿Qué intereses locales? Expolicías vinculados a los militares, neo-nazis, activistas de derecha, en fin, todos aquellos sectores de la sociedad argentina que siempre han visto a los judíos como un cuerpo diabólico y ajeno, que han atacado a instituciones judías y a profesiones “judías”, como el psicoanálisis.

Pude constatar personalmente lo profundo de la animosidad, cuando me llegó el siguiente anónimo después de publicar un artículo sobre la AMIA en la página editorial del New York Times (“Alongside the Dead in Argentina”). Cito textualmente:

Listen to me, Jewess. It is an affront to all Spanish peoples, especially to us Argentines, to even remotely imply that there is such a thing as Argentine...Jews...As a former Argentine army officer I am insulted by your inferences that these creatures have done anything positive for Argentina. They are known throughout the world as pariahs and manipulators ...

El autor de la misiva seguramente estaba entre los que aplaudieron el hecho que poco después del estallido ciertos clubes deportivos rehusaron competir con sus contrapartes israelitas, ciertos vecinos de escuelas judías juntaron firmas para pedirles que se fueran, y ciertos comentaristas sugirieron que sería prudente aislar a todas las instituciones judeoargentinas en una suerte de ghetto criollo, una zona remota y abandonada del puerto de Buenos Aires. Los fuegos del prejuicio habían sido avivados, y donde se discrimina a un grupo no se tarda en discriminar a otro. Al terminar la misa recordatoria en honor a las víctimas de la AMIA, el cardenal primado de la Argentina, contestando a la pregunta de un periodista sobre la expansión de derechos para grupos desprotegidos en la nueva constitución que se estaba debatiendo en aquel momento, contestó que los homosexuales quizá se sentirían más cómodos en su propio país — establecido en una isla - y con su propia constitución. En la misma época, un comité gubernamental encargado de preparar un nuevo programa de educación nacional fue forzado a eliminar las referencias abiertas a la educacíon sexual, y a reemplazar la palabra "género" (gender) por “sexo”, ya que "género" fue percibido por fuerzas conservadoras y eclesiásticas como un concepto contrario al matrimonio, a la familia, y a los buenos modales (Franco 281). 
Por el otro lado, poco después de la explosión hubo una manifestación masiva de repudio y solidaridad en la que participaron miles de argentinos de todos los orígenes y credos. También hubo múltiples expresiones de apoyo de la comunidad intelectual, una comunidad que conoce los peligros del asesinato y la destrucción como formas de coerción política y cultural demasiado bien. Tomás Eloy Martínez alertó a sus compatriotas en un ensayo intitulado, "El miedo a las víctimas”, aparecido en el diario Página Doce, que no hace tanto miles de argentinos desaparecieron bajo la más brutal de las dictaduras, y los escuadrones de muerte pululaban por las calles de Buenos Aires. El ataque a la AMIA no puede ser desvinculado del pasado, insistía Martínez. Los argentinos querían olvidar lo que ocurrió entonces, y ahora también quieren olvidar, refugiándose en llamamientos cobardes para aislar a los judíos.

¿Cómo salir ahora de nuestra larga historia de impunidades? Escondíamos las impunidades del pasado sin hablar demasiado de ellas, como se hacía con los idiotas en los altillos, pero ahora todos los fantasmas están afuera, acosándonos ... Si no hubiéramos consentido ayer a la impunidad, a lo mejor hoy sería más fácil encontrar a los culpables. Uno busca salidas aunque no las ve. La única que nos queda es no olvidar, pero lo terrible es que también el olvido ha comenzado (32).

Abelardo Castillo expresa sentimientos similares en su artículo, "La muerta a la vuelta de la esquina”:

Tal vez el lector advierta que todavía no he dicho AMIA ni he dicho judíos. Muy bien, es deliberado. Por que hacer de esto una nueva matanza de judíos ... es alejarnos del problema y seguir pensando que la muerte, la violencia criminal, el odio, no nos atañen. Lo que pasó ayer es un problema argentino ... Sé que su nombre es genocidio y que sucedió en nuestro país porque era posible (Clarín 20 julio 1994).

Las palabras de repudio de Ernesto Sábato, ex-presidente de la Comisión Nacional Sobre la Desaparición de Personas, recordaban sus palabras en el informe final de la comisión, llamado Nunca Más: "No podemos callar ante lo que hemos oído, leído, y registrado" (7).

Muchos argentinos han dicho "nunca más”. "Hoy”, escribe el periodista Sergio Kiernan, "un gran número de ciudadanos considera que el atentado a la AMIA no es un asunto exclusivamente judío. Su resolución es una prioridad para la sociedad argentina en general, un símbolo de lo que aqueja al país” (Still No Justice 12). La agrupación que ha llevado la lucha adelante con más militancia es Memoria Activa, una asociación de judíos y no-judíos, muchos de ellos familiares de los que murieron en la explosión.

Memoria Activa acusa al gobierno de consentir a la indiferencia de los que saben y se callan, de encubrir la conexión local, de obstaculizar la investigación que supuestamente se está llevandose a cabo. Las madres y esposas que encabezan el grupo han sido llamadas las madres de la Calle Pasteur, en analogía con las legendarias Madres de la Plaza de Mayo que se reunían en la plaza principal de Buenos Aires, exigiendo saber dónde estaban sus hijos desaparecidos. Cada lunes desde el día del atentado, exactamente a las 9:50 de la mañana, 
los activistas y simpatizantes de Memoria Activa se reúnen en otra plaza bonaerense, frente a los Tribunales, bajo el lema del mandato bíblico del Deuteronomio, "justicia, justicia perseguirás”, en hebreo, tzedek, tzedek tirdof.

Los testimonios de los que han participado en los actos de Memoria Activa constituyen un “documento nacional contra la impunidad” quizá a la altura de los grandes testimonios de la literatura latinoamericana contemporánea, entre ellos Preso sin nombre, celda sin número (1980) del recientemente fallecido Jacobo Timerman, que denunciaba el antisemitismo hitlerista y las tácticas genocidas de los militares durante los años setenta. Dichos testimonios conforman una lista de honor de argentinos — líderes gremiales, periodistas, abogados, dirigentes juveniles, artistas, activistas pro-derechos humanos, rabinos, diputados, médicos, historiadores, escritores, Madres de la Plaza de Mayo- que rehúsan callarse porque quieren "vivir en un país digno" (Documento 5). Cito las palabras de Laura Bonaparte de la Madres de la Plaza de Mayo, del lunes 20 de octubre de 1997:

Hoy es el día después del día de la madre. Y esta sociedad está armando el cuerpo destrozado de su institución madre. Y debemos hacerlo entre todos. Porque ocurrió en la casa de cada uno de nosotros. Todos descubrimos horrorizados la persistencia del terrorismo de Estado. ¿Por qué llamarlo de otra manera si el Estado es el que no nos permite armar este cuerpo, cuya ausencia denuncia el crimen? La AMIA no nos abandonó, fue asesinada ... El crimen se perpetúa hasta que la verdad no sea testimonio en la justicia (Memoria Activa 58).

El conflicto entre Memoria Activa, la dirigencia de la comunidad judía, y el gobierno de Menem se hizo público durante la ceremonia para conmemorar el tercer aniversario de la bomba en 1997, cuando más de treinta mil personas ovacionaron el discurso de Laura Ginsburg, tesorera de Memoria Activa, y, en presencia de varios miembros del gabinete nacional, interrumpieron la intervención de Rubén Beraja, entonces presidente de la Delegación de Asociaciones Israelitas Argentinas (DAIA), organización que representa a la judeidad argentina ante el gobierno.

Cierro los ojos e imagino que son las 12 de la noche de aquel 18 de julio, dijo Ginsberg. Todos dormimos los sueños, todos tenemos a nuestras familias enteras y todos proyectamos para el día siguiente la irrespetuosa locura de vivir, el desafiante pensamiento de vivir, el ilusorio deseo de vivir. Pero cuando los abro me encuentro 3 años después con la irrespetuosa locura de querer justicia, con el desafiante pensamiento de exigir justicia, con el ilusorio deseo del nunca más ... Y porque esa mañana salieron de sus casas como todas las mañanas y no volvieron MERECEN JUSTICIA ... Y porque la ley de la vida dice que los padres no entierran a sus hijos RECLAMAMOS JUSTICIA ... Y merecen justicia, porque ... sólo después de HACER JUSTICIA nuestros muertos podrán descansar en paz. LOS MUERTOS DE LA AMIA: PRESENTES (Memoria Activa 16-17).

Por su fuerza dramática como testimonio de la impotencia contenida, del grito desesperado ante la injusticia, el discurso de Ginsberg se ha convertido en un texto representativo de la escritura judeoargentina post-AMIA. Significativamente, aparece como la selección final en una antología de autores judíos argentinos publicada el año 
pasado (1999) en una colección dirigida por David Viñas y Gisela Heffes. Las primeras selecciones, de nombres ya clásicos como Alberto Gerchunoff, Enrique Dickman, Samuel Eichelbaum, y Carlos Grünberg no son extentas de los desengaños y las vicisitudes que sufrieron los inmigrantes en la Tierra de Promisión argentina. No obstante, todavía proyectan el optimismo de principios del siglo veinte, de la utopía futura como posibilidad. Las palabras de Ginsberg, en cambio, parten de un instante en que el mundo se hundió bajo los escombros. Alternan entre dos devenires: el antes y después de un día y una hora imborrable, e invierten "el orden de las cosas: los ojos abiertos, insomnes, miran hacia atrás y transforman el ayer en un sueño lejano, el de los ojos cerrados, el que fue consumido por un presente irreparable" (Judíos / argentinos / escritores 35).

Cuán irreparable es este presente fue demostrado en mayo de 1999, al inaugurarse un nuevo edificio de la AMIA, levantado sobre las cenizas del otro. El nuevo edificio es un búnker antiterrorista de cemento armado color gris, diseñado con el más sofisticado sistema de seguridad para evitar que una bomba lo destruya por segunda vez. A pesar de las palabras conciliadoras de las autoridades — "volvemos a nuestra casa" — los familiares de las víctimas no asistieron al acto de apertura. "Están construyendo sobre la sangre de nuestros seres queridos”, dijo uno de ellos. No había que tocar los escombros, la nueva sede no representa un triunfo sobre la vida (Young 18). Por eso cada lunes, Memoria Activa sigue reuniéndose en la plaza frente a los Tribunales, ahora llamada La Plaza de la Memoria.

Más de cinco años después del atentado, en los umbrales del siglo XXI, el ataque a la AMIA plantea difíciles interrogatorios sobre el pluralismo en la Argentina. Para muchos “modernizar” al país equivale a privatizarlo (como en el siglo XIX equivalía a poblarlo). Pero para otros, la modernización tiene que ser más profunda, llegando hasta las raíces mismas de la sociedad argentina. Beatriz Sarlo pregunta:

¿Hay una idea de nación que sea imposible compartir con la nación de las dictaduras? La historia del siglo XX, nos previene contra una idea de nación que no esté sustentada en, por lo menos, ... dos ideas: la de la tolerancia hacia todas las diferencias que se incluyen en el territorio de una nación; la de los valores de solidaridad y de responsabilidad colectiva (109).

¿Será la Argentina un espacio de unicidad —una religión, una lengua, un color?, ¿ O será un caleidoscópico espacio de multiplicidad, donde se celebren las diferencias religiosas y raciales, y donde argentinos judíos y no-judíos no tengan que llorar a sus muertos asesinados? ${ }^{1}$

\footnotetext{
${ }^{1}$ Agradezco la ayuda de Jacobo Kovadloff, Asesor Latinoaméricano del Comité Judío Americano, y de Anita Weinstein, Directora del Centro Mark Turkow para la Documentación del Judaísmo Argentino y sobreviviente de la bomba, en la colección de materiales para este ensayo. Susy Kreiman fue la Directora del Servicio Social Comunitario de la AMIA. Murió en el estallido en cumplimiento de sus funciones.
} 
BIBLIOGRAFÍA

Aizenberg, Edna. “Alongside the Dead in Argentina”. New York Times, Op-Ed page, (2 agosto 1994).

Castillo, Abelardo. "La muerte a la vuelta de la esquina”. Clarín (20 julio 1994).

Documento nacional contra la impunidad: Memoria Activa-Testimonios. Buenos Aires: Página Doce, 1999.

Feierstein, Ricardo. “Aventuras de un apellido”. Noaj 2/2 (1988): 4-6.

Franco, Jean. “Defrocking the Vatican: Feminism's Secular Project”. Cultures of Politics, Politics of Culture. Sonia E. Álvarez, Evelina Dagnino, y Arturo Escobar, eds. Boulder, CO: Westview, 1998. 278-289.

Heffes, Gisela (ed.). Judíos / argentinos / escritores. Dirección general, David Viñas. Buenos Aires: Atril, 1999.

Kiernan, Sergio. Still No Justice: Four Years After the AMIA Bombing. Nueva York: American Jewish Committee, 1998.

Kovadloff, Santiago. "Un lugar en el tiempo: La Argentina como vivencia de los judíos”. Por un futuro imperfecto. Buenos Aires: Botella al Mar, 1987. 85-98.

Martínez, Tomás Eloy. “El miedo a las víctimas”. Página doce (21 agosto 1994): 32. Memoria Activa: cuatro años de impunidad. Buenos Aires: La Página, 1998.

Nunca más: Informe de la Comision Nacional sobre la Desaparición de Personas. Buenos Aires: EUDEBA, 1986.

Sarlo, Beatríz. "La nación en el fin de siglo". Instantáneas: medios, ciudad y costumbres en el fin de siglo. Buenos Aires: Ariel, 1996. 107-109.

Steimberg, Alicia. Cuando digo Magdalena. Buenos Aires: Planeta, 1992.

Young, Gerardo. “La AMIA, 1,772 días después”. Clarín (27 mayo 1999): 1-19. 